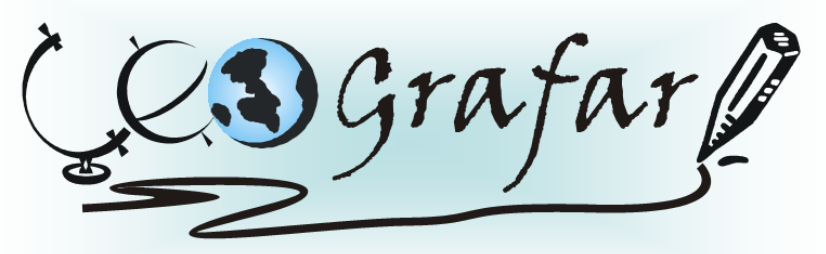

Revista Eletrônica do Programa de Pós-Graduação em Geografia - UFPR

\title{
DETERMINAÇÃO DO INÍCIO E TÉRMINO DA ESTAÇÃO CHUVOSA NO ESTADO DO PARANÁ
}

\author{
LÍVIA MARIA PEDERZINI PEREIRA ${ }^{1}$. \\ PAULO HENRIQUE CARAMORI ${ }^{2}$ \\ WILIAN DA SILVA RICCE ${ }^{3}$ \\ DANILO AUGUSTO B. DA SILVA \\ JOÃO HENRIQUE CAVIGLIONE ${ }^{5}$
}

\begin{abstract}
RESUMO: A precipitação é uma das variáveis meteorológicas mais importantes para os estudos climáticos das diversas regiões do Brasil. O conhecimento prévio do comportamento temporal e espacial da precipitação possibilita melhor planejamento das atividades agrícolas, reduzindo perdas e melhorando as condições de produção. Este trabalho teve como finalidade estimar as datas de início e fim da estação chuvosa no Estado do Paraná, que delimitam o período em que ocorre a safra de verão. Os dados analisados referem-se a 117 estações pluviométricas, bem distribuídas espacialmente, pertencentes ao Instituto Agronômico do Paraná (IAPAR) e Superintendência de Desenvolvimento de Recursos Hídricos e Saneamento (SUDERHSA). Para determinação do início da estação chuvosa o critério estabelece que deva chover pelo menos $20 \mathrm{~mm}$ em 2 dias consecutivos, a partir de $1^{\circ}$ de julho e, em um período subsequiente de 30 dias não deverá ocorrer mais de 10 dias consecutivos sem precipitação. Para o término da estação chuvosa foi estabelecida a primeira data após o dia $1^{\circ}$ de março, a partir da qual não houve chuva por um período subseqüente de 10 dias. $O$ início da estação chuvosa se estabeleceu entre o primeiro decêndio de agosto no litoral e ocorreu progressivamente mais tarde nas demais regiões, iniciando-se no norte do estado no primeiro decêndio de outubro. Já o fim da estação chuvosa ocorreu entre o segundo decêndio de março no norte e o primeiro decêndio de maio nas áreas localizadas no sul. Os resultados obtidos mostram a característica de transição climática do Paraná, onde se verifica maior diferenciação entre estação seca e chuvosa no norte e oeste, enquanto que no sul as chuvas são mais uniformemente distribuídas e se prolongam ao longo do ano.
\end{abstract}

Palavras - chave: Precipitação, Estudos climáticos, Variabilidade.

\section{DETERMINATION OF THE BEGINNING AND ENDING OF THE RAINY SEASON IN PARANÁ STATE, BRAZIL}

\begin{abstract}
Rainfall is one of the more important meteorological variables in climate studies of several regions in Brazil. The previous knowledge of the spatial and temporal distribution of rain makes possible a better planning of the agricultural practices, reducing losses and improving farming conditions. This study had as objective to define the dates of beginning and ending of the rainy season in Paraná State, southern Brazil, which delimits the period when the summer crops are grown. The rainfall data was obtained from 117 weather stations, spatially distributed accross the State, from the Instituto Agronômico do Paraná (IAPAR) and Superintendência de Desenvolvimento de Recursos Hídricos e Saneamento (SUDERHSA). For determination of the beginning of the

\footnotetext{
${ }^{1}$ Graduanda em Geografia, Universidade Estadual de Londrina (UEL), Bolsista CNPq/IAPAR, Londrina - PR

${ }^{2} \mathrm{PhD}$. Agrometeorologia, Pesquisador do Instituto Agronômico do Paraná, IAPAR, Londrina - PR.

${ }^{3}$ Ms. Agronomia, Pesquisador Agroconsult Ltda, Londrina - PR.

${ }_{5}^{4}$ Analista de sistemas, Pesquisador visitante Fundação ABC, Londrina - PR.

${ }^{5}$ Ms. Geoprocessamento, Pesquisador do Instituto Agronômico do Paraná, IAPAR, Londrina - PR.
} 
rainy season the criterion establishes that it must rain at least $20 \mathrm{~mm}$ in 2 consecutive days, from 1 st of July and, in a subsequent period of 30 days there must not occur 10 consecutive days without precipitation. The end of the rainy season was assumed to be the first date after the 1st of March, from which it did not have rain for a subsequent period of 10 days. The beginning of the rainy season was established as occurring between the first ten-day period of August, in the state coast, and the first ten-day period of October, in the northern areas. The end of the rainy season occurred between the first ten-day period of March in the north and the first ten-day period of May in the southern areas. The results show the characteristic of climatic transition of Paraná state, where there is a big difference in rainfall between the dry winter and the rainy summer season in the north and west, while in the south the rain is more uniformly distributed along the year.

Key words: rainfall, climatic studies, variability.

\section{INTRODUÇÃO}

A precipitação pluvial é o principal elemento que afeta a produtividade agrícola no Estado do Paraná. Devido ao fato de localizar-se em região de transição climática, a irregularidade das chuvas dificulta, por um lado, o estabelecimento das culturas e, por outro lado, os excessos de precipitações durante a colheita afetam a qualidade e o volume da produção (CAVIGLIONE et al., 2000; CARAMORI et al., 2001).

Em escala regional e local, as chuvas variam em função do relevo e da formação de áreas de instabilidade, que fazem com que chova abundantemente em uma face da bacia e a alguns quilômetros de distância não se registre chuvas. Para que haja precipitações mais uniformes é necessário o deslocamento de massas polares de grande intensidade, que formam frentes frias com grandes quantidades de água precipitável.

A decisão de realizar a semeadura ou o plantio é crucial para garantir um bom potencial produtivo. Muitos agricultores realizam esta operação em solo seco ou com baixo teor de umidade, aguardando uma precipitação suficiente para causar a germinação e emergência das culturas. Entretanto, devido à irregularidade no início da estação chuvosa, muitas vezes as chuvas não ocorrem ou são insuficientes para propiciar o estabelecimento da cultura, causando queda na produção agrícola, o que ocasiona um desequilíbrio socioeconômico na região.

O conhecimento do início e fim da estação chuvosa auxilia no planejamento prévio das operações agrícolas, para que práticas como o preparo do solo, terraceamento e aplicação do calcário sejam feitas no período correto, como também no planejamento de espécies a serem cultivadas. Da mesma forma, o período final da maturação das culturas, de preferência, não deve coincidir com a época chuvosa, pois assim se evita a perda de qualidade de grãos. 
O melhor conhecimento do clima e de sua variabilidade no espaço urbano também é importante para fornecer informações a setores do governo no sentido de se determinar estratégicas para diminuição de impactos à sociedade, contribuindo na tomada de decisões referente à construção civil, geração hidroelétrica, saúde e questões ambientais.

Vários estudos foram realizados objetivando determinar o início e fim da estação chuvosa, assim como sua duração. Barbieri (2005) utilizou a Radiação de Onda Longa Emergente (ROL), que é uma medida da convecção, a qual esta associada às chuvas, e dados diários de precipitação, visando um melhor conhecimento do início e fim da estação chuvosa para as regiões Sul e Sudeste do Brasil. O autor observou que pelos dados de ROL, a estação chuvosa na Região Sudeste ocorre do final de setembro a início de maio. Já através dos dados de precipitação, constatou que a estação chuvosa ocorre entre os meses de outubro a março. A Região Sul do Brasil não apresentou uma estação chuvosa bem definida, o que pode ser constatado através da análise climatológica, devido à distribuição uniforme da precipitação durante todo o ano.

Machado et al. (1996) caracterizaram a estação chuvosa em nove regiões consideradas climatologicamente homogêneas para o Estado de Minas Gerais. Os autores propuseram um critério baseado em dados diários de precipitação e ocorrência de veranicos, evidenciando que em locais em que o período chuvoso começou precocemente, houve também uma tendência deste terminar mais cedo, e quando a estação chuvosa começou tardiamente, ocorreu um período chuvoso mais longo.

Nery et al. (1996) caracterizaram a precipitação no Estado do Paraná, utilizando Análise Multivariada e o Método de Análise de Fourier, definindo os períodos mais chuvosos e mais secos, em cada região. Concluíram que a precipitação no Estado tem dois regimes muito bem marcados. Nas regiões nordeste, leste e sudeste houve uma estrutura de máximas no verão, ocorrendo médias mais elevadas em janeiro e nas regiões oeste e central ocorreu precipitação mais uniforme ao longo do ano.

Sansigolo (1996) fez um estudo detalhado da variabilidade interanual dos eventos relacionados à estação chuvosa no Estado de São Paulo, no período de 1940 a 1992. Baseado em dados diários de precipitação, utilizou como critério para o início da estação, a primeira data após determinada data específica, em que ocorreu $20 \mathrm{~mm}$ de chuva em dois dias consecutivos, desde que não houvesse períodos secos superiores a sete dias durantes os 30 dias subseqüientes. O fim das chuvas foi determinado pela primeira ocorrência de uma seqüência de 
10 dias secos, após uma data determinada. As datas médias encontradas foram 27 de setembro para o início e 4 de março para o fim. Esse critério também foi utilizado por Santana (2007), para caracterizar o período chuvoso no Estado de Minas Gerais, demonstrando que é possível obter boas estimativas probabilísticas a partir de registros diários de precipitação através de um método direto simples de análise.

Este trabalho tem como objetivo a determinação do início e término da estação chuvosa, por meio de uma análise de dados meteorológicos históricos de diferentes locais do Estado do Paraná, no intuito de fornecer informações relevantes para a climatologia e a agricultura paranaense.

\section{MATERIAL E MÉTODOS}

As séries de dados diários de precipitação usados neste trabalho foram referentes ao período de 1976 a 2006, provenientes de 30 estações meteorológicas do Instituto Agronômico do Paraná (IAPAR) e 88 estações pluviométricas da Superintendência de Desenvolvimento de Recursos Hídricos e Saneamento (SUDERHSA), distribuídas no território paranaense (Figura $1)$.

\section{FIGURA 1. LOCALIZAÇÃO DAS ESTAÇÕES METEOROLÓGICAS.}

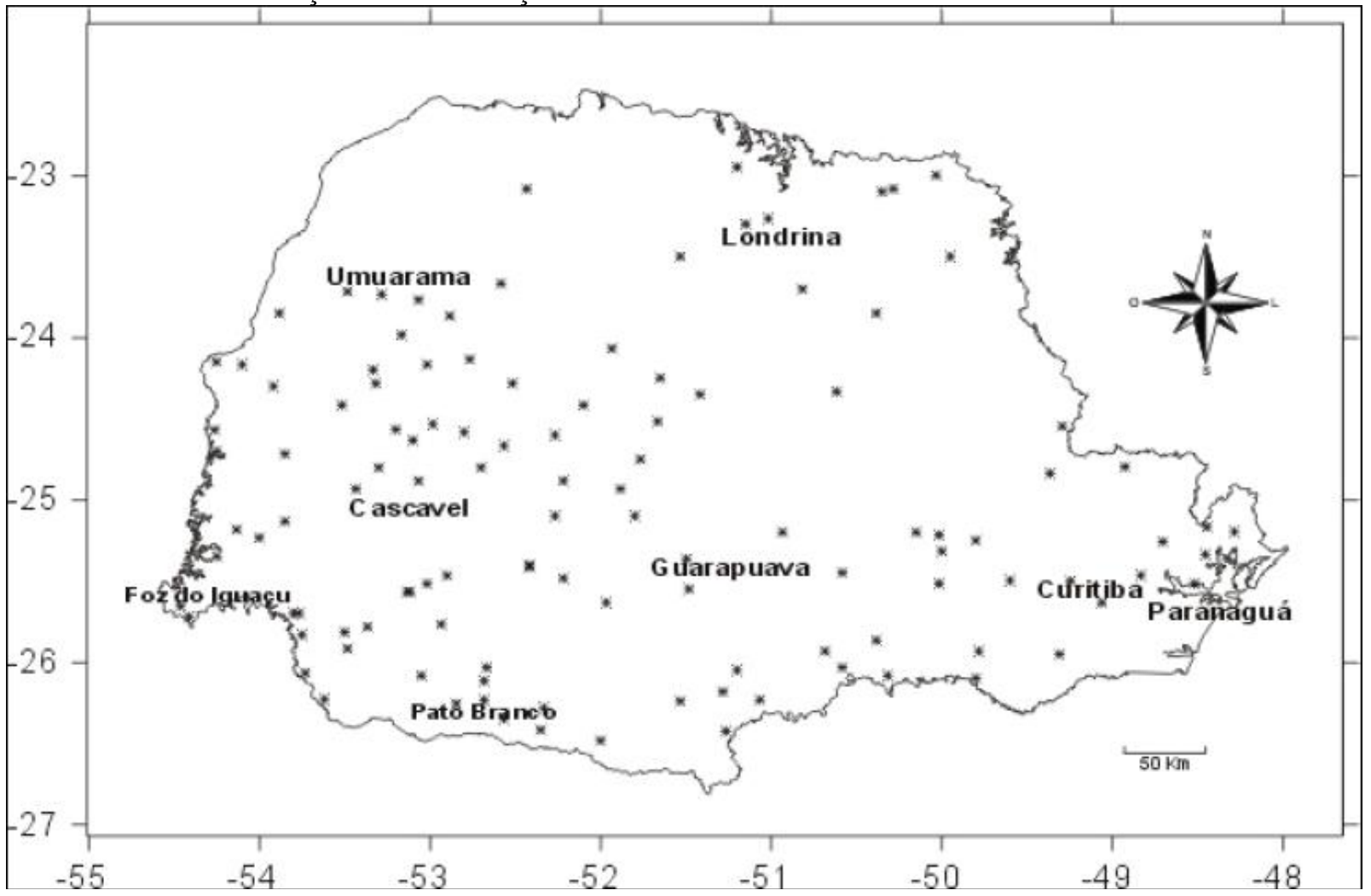


Os dados foram analisados para evitar períodos com falhas ou eventuais erros no banco de dados.

Neste estudo adotou-se para a definição do inicio da estação chuvosa o critério utilizado por Sansigolo (1989), que estabelece que deva chover pelo menos $\mathrm{X} \mathrm{mm} \mathrm{em} \mathrm{T}$ dias consecutivos, a partir da data $\mathrm{D}$ e, em um período subseqüente de $\mathrm{M}$ dias, não deverá ocorrer mais de $\mathrm{N}$ dias consecutivos sem precipitação. Nas análises realizadas, $\mathrm{D}=1^{\circ}$ de julho, $\mathrm{X}=20$ mm, $\mathrm{T}=2$ dias, $\mathrm{M}=30$ dias e $\mathrm{N}=10$ dias, uma vez que as necessidades hídricas das plantas podem, em períodos de até dez dias, serem satisfeitas pela água armazenada no solo (MACHADO et al., 1996).

Já para o término da estação chuvosa, com base no padrão de distribuição das chuvas ao longo do ano (CAVIGLIONE et al., 2000), escolheu-se a data após o dia $1^{\circ}$ de março, a partir da qual não houve chuva por um período subseqüente de 10 dias, considerando como dia chuvoso a precipitação de, pelo menos, $1 \mathrm{~mm}$. Posteriormente os resultados foram agrupados por decêndios.

Com as datas da estação chuvosa determinadas, foram calculados a duração da estação chuvosa em dias, obtida pela diferença entre o fim e início do período chuvoso e os totais de precipitação durante a estação chuvosa, obtendo assim um estudo detalhado sobre o comportamento da precipitação no Estado do Paraná.

Utilizando o software Surfer versão 8.0, foram gerados mapas anuais com os dados disponíveis para cada ano. Em seguida os dados foram interpolados pelo método Kriging obtendo uma grade de 2.500 pontos para cada ano em um total de 30 anos. A Krigagem leva em consideração o número de amostras utilizadas; as posições das amostras na área a ser avaliada e as distâncias entre as amostras e a zona a ser estimada (ANDRIOTTI, J. L. S., 2004 apud SOTÉRIO, P. W. et al., 2005). Com os grids anuais foi gerada uma média para cada um dos 2.500 pontos e posteriormente se obteve um novo mapa com a média dos anos.

\section{RESULTADOS E DISCUSSÃO}

Com os 2.500 pontos gerados a partir dos dados originais, foi possível gerar valores onde não havia estação meteorológica e também homogeneizar a duração das séries históricas. $\mathrm{O}$ Estado foi dividido em sete regiões homogêneas quanto ao início da estação chuvosa, iniciando 
no primeiro decêndio de agosto no litoral, passando para o segundo e terceiro decêndios de agosto no sul do estado e tornando-se progressivamente mais tardia em direção ao norte. Nesta região, a estação chuvosa se estabelece no último decêndio de setembro ou no primeiro decêndio de outubro (Figura 2).

FIGURA 2. DECÊNDIOS EM QUE OCORRE O INÍCIO DA ESTAÇÃO CHUVOSA NO PARANÁ.

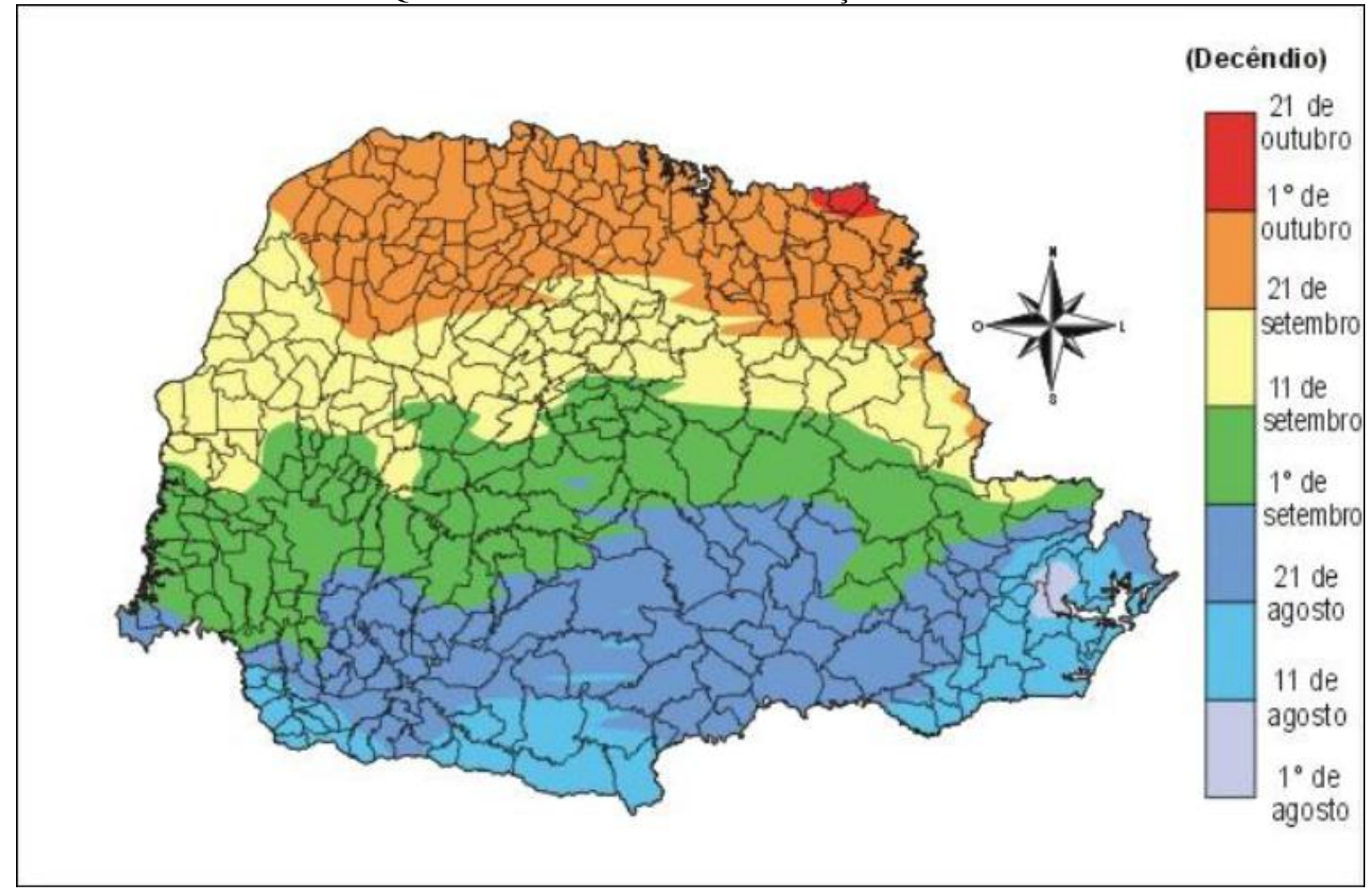

A data climatológica para o fim da estação chuvosa ocorre entre o segundo decêndio de março e o último decêndio de maio. As chuvas se encerram no segundo e terceiro decêndio de março no noroeste e norte do Estado, passando para o primeiro e segundo decêndio de maio nas demais regiões, com exceção do litoral, que tem o término da estação chuvosa de 21 a 31 de maio (Figura 3). 
FIGURA 3. DECÊNDIOS EM QUE OCORRE O FIM DA ESTAÇÃO CHUVOSA NO ESTADO DO PARANÁ.

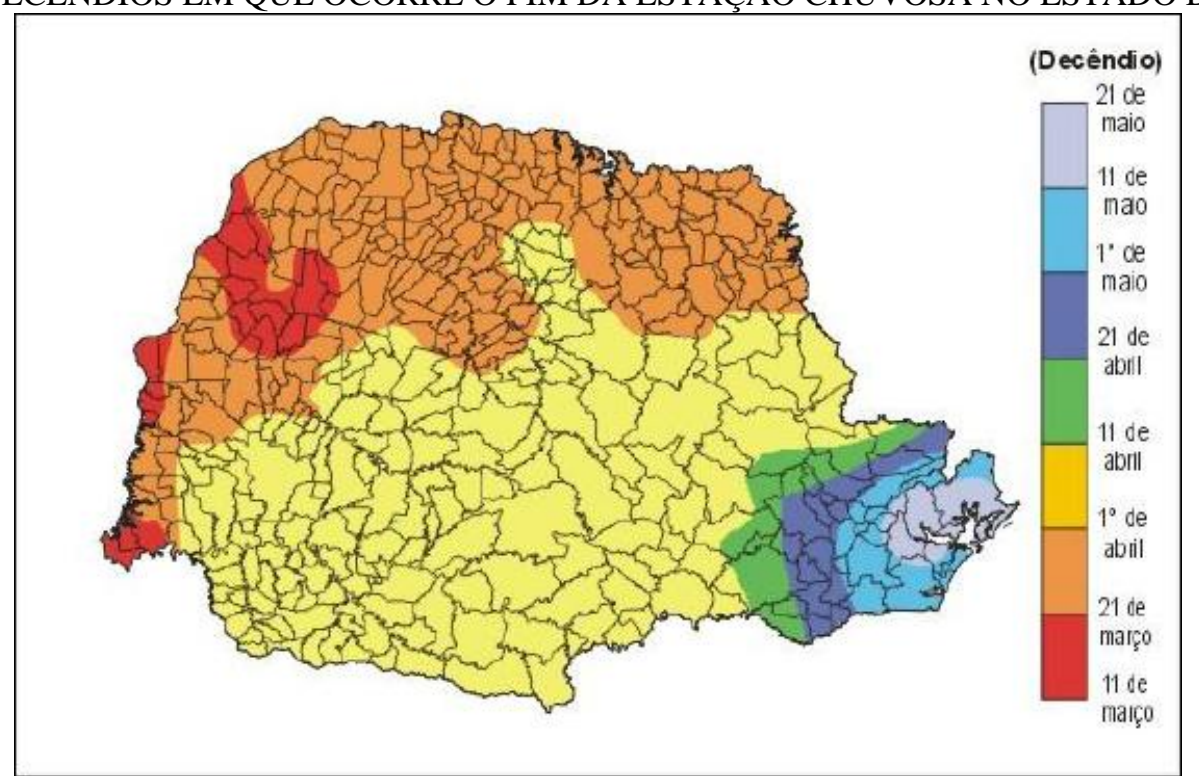

A região oeste e parte do norte apresentam a estação chuvosa mais seca, com os menores índices de duração de dias de chuva, variando de 150 a 160 dias; em seguida vem a região centro-oeste e norte com um período de 160 a 170 dias. Nas demais regiões as precipitações relativamente altas se prolongam ao longo do ano, chegando a 210 dias no litoral (Figura 4). Observou-se por meio da relação entre início, fim e duração da estação chuvosa que nos locais onde esta começa mais cedo tende a terminar mais tarde, ocasionando em uma estação chuvosa mais longa. De maneira distinta, quando se têm períodos chuvosos iniciados tardiamente, temse uma estação chuvosa mais curta também pelo seu término ocorrer antes.

FIGURA 4. DURAÇÃO DA ESTAÇÃO CHUVOSA (DIAS) NO ESTADO DO PARANÁ.

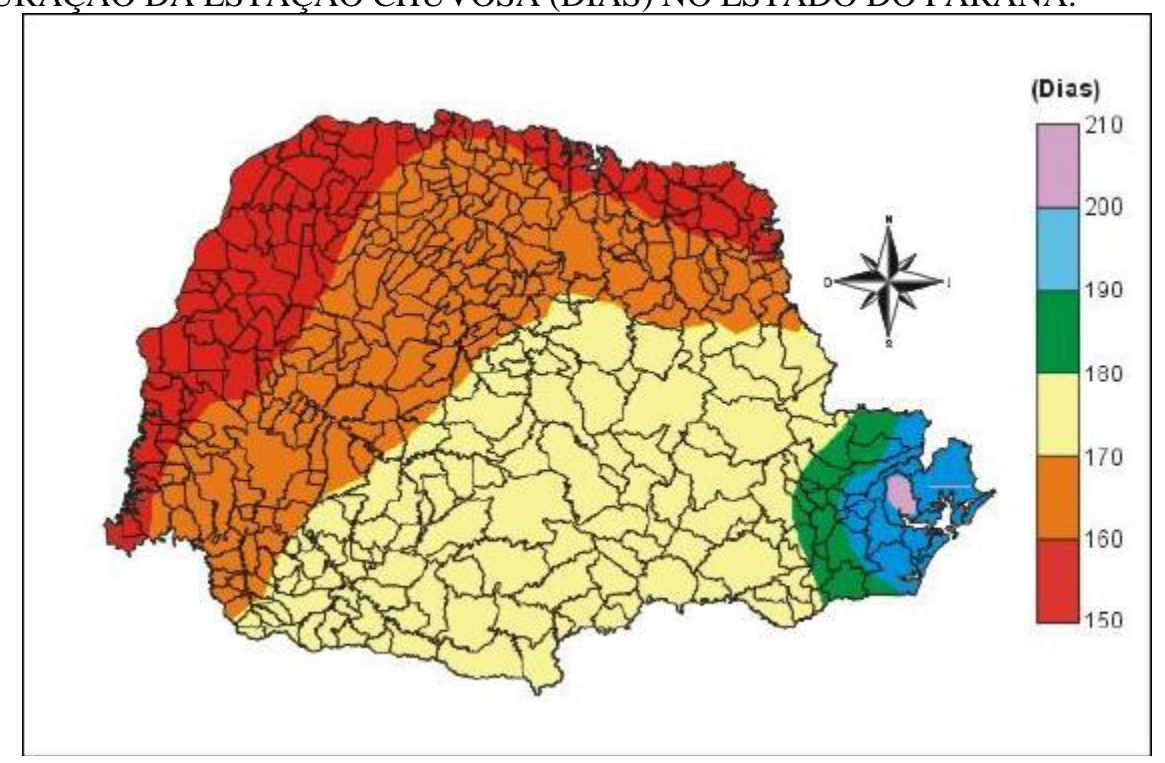


Com base na análise dos totais prováveis de chuva durante a estação chuvosa observouse uma grande diferença entre as regiões quanto ao volume de precipitação, obtendo-se mínimo de 800 a $900 \mathrm{~mm}$ no extremo noroeste, $900 \mathrm{~mm}$ a $1.100 \mathrm{~mm}$ no norte, $1000 \mathrm{~mm}$ a $1.200 \mathrm{~mm}$ no centro sul até $1.700 \mathrm{~mm}$ no litoral (Figura 5).

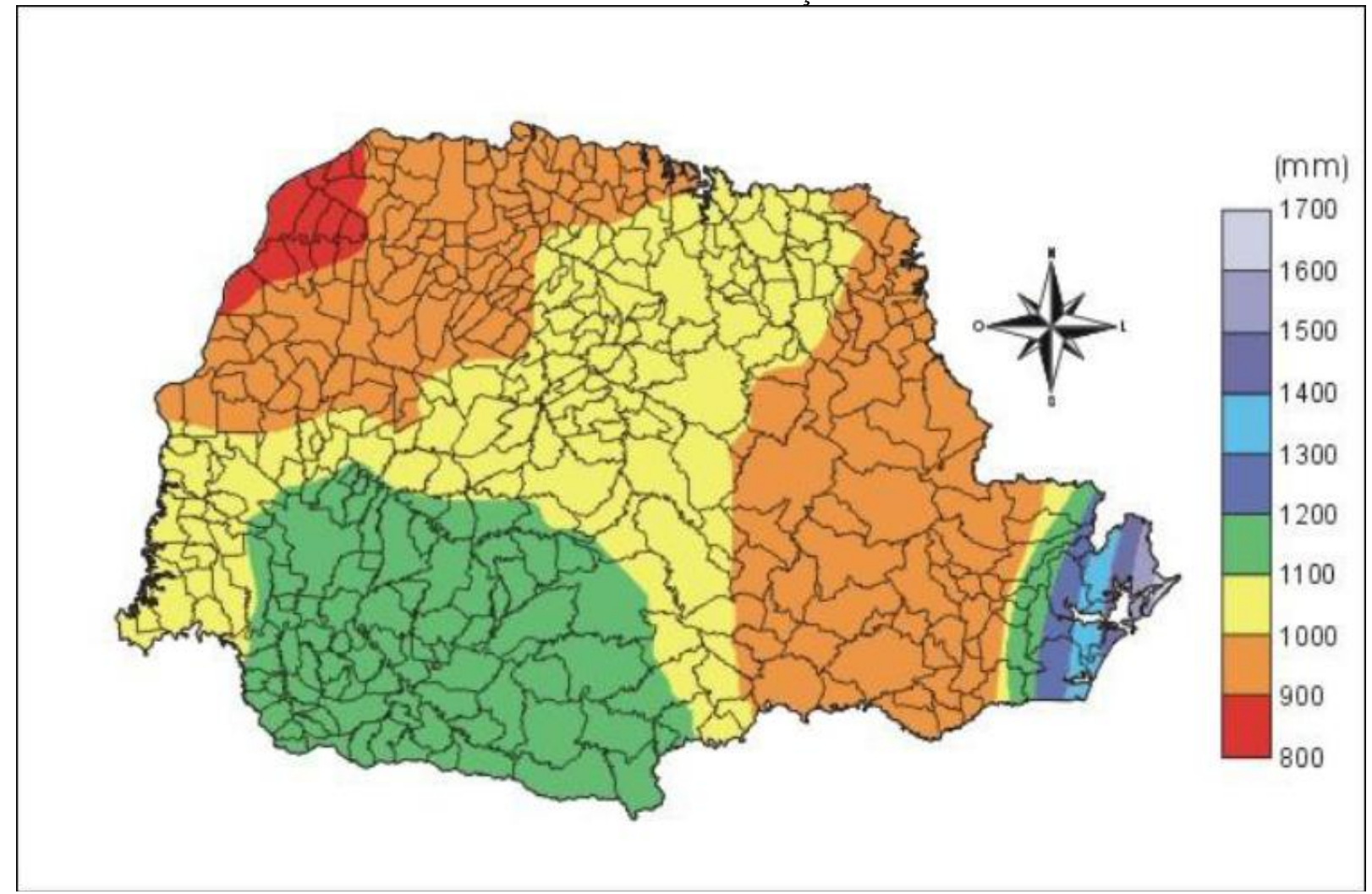

Pode-se observar que no norte e oeste do Estado o início e fim da estação chuvosa são bem definidos, e à medida que se desloca em direção ao centro há uma mudança que demonstra a transição climática que ocorre dentro do território paranaense. Nas áreas de clima temperado e altitudes elevadas do sul do Estado não se caracterizou uma estação seca bem definida, embora ocorra maior volume de precipitações durante a primavera e o verão. Já o litoral é uma área distinta, que se encontra em regime de chuvas o ano inteiro, devido à alta umidade trazida pela massa de ar tropical atlântica e pela brisa marítima.

Atuando como obstáculos orográficos, as grandes escarpas que delimitam o primeiro, o segundo e o terceiro planaltos paranaenses são de grande importância na distribuição das precipitações pluviais, pois forçam a umidade transportada pelos ventos marítimos que sopram de E, NE e SE como alísio desviado pela serra do Mar (Figura 6). 
Assim, o segundo planalto, ou escarpa devoniana, recebe mais chuva que o primeiro planalto, que fica localizado diante da cuesta. Enquanto no terceiro planalto, é onde mais chove conseqüente da sua posição de latitude e longitude, além de ser uma área de várias zonas climáticas (MAACK, 2002).

FIGURA 6. HIPSOMETRIA DO ESTADO DO PARANÁ DESTACANDO OS PLANALTOS, AS VARIAÇÕES DE ALTITUDE E A HIDROLOGIA.

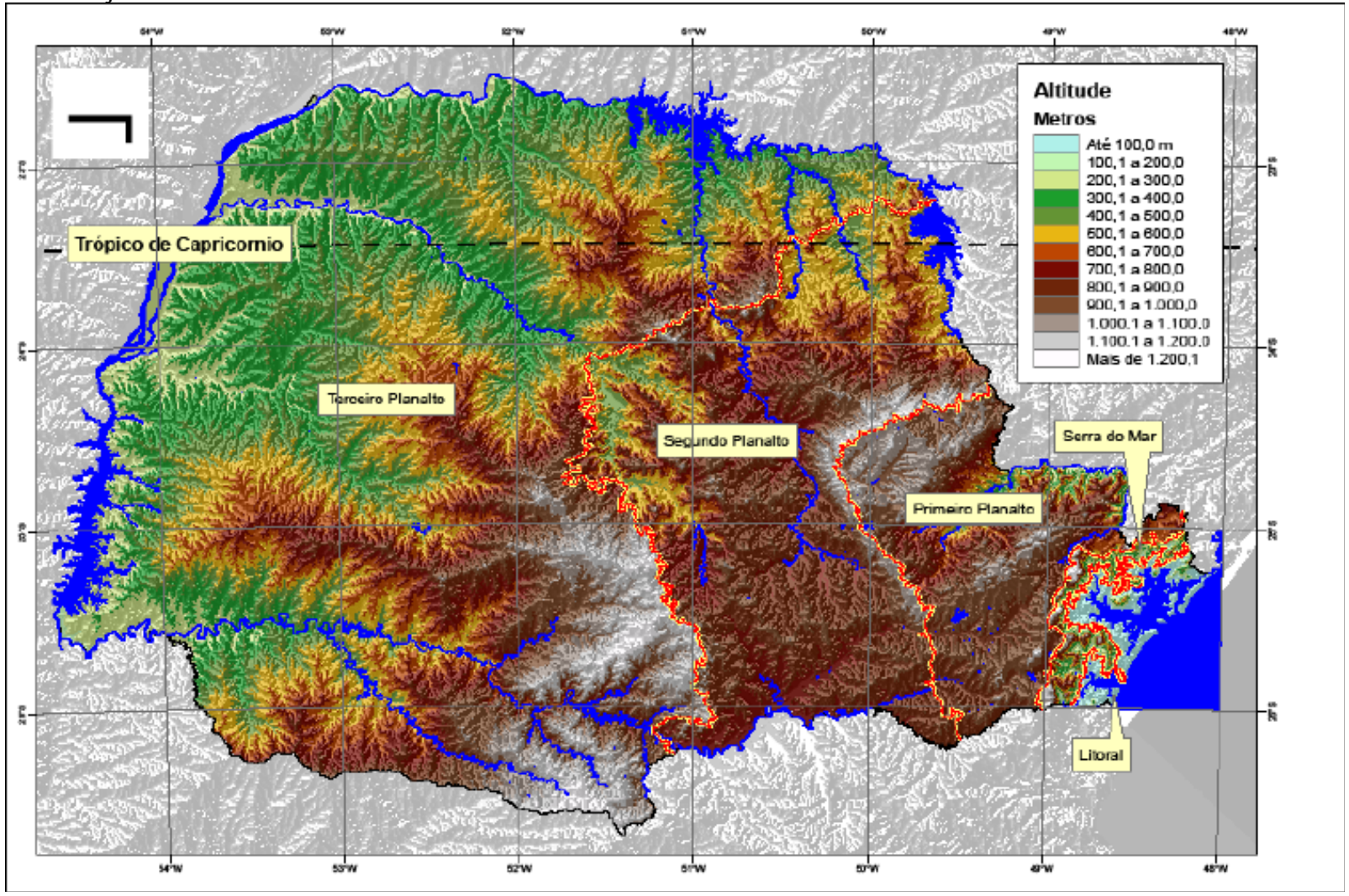

Os ventos alísios, gerados pela rotação da Terra e a passagem de centros de alta pressão sobre o oceano, fazem com que os ventos tenham sua direção voltada para o continente, trazendo a umidade marítima para a faixa leste e exercendo enorme influência no litoral.

Na Região Sul atuam as massas de ar Tropical Atlântica, Polar Atlântica, Tropical Continental e Equatorial Continental (MONTEIRO, 1963 apud VERÍSSIMO e MENDONÇA, 2004). No período de primavera - verão, a Massa Tropical Atlântica é a predominante, caracterizando este período do ano como úmido e de temperatura elevada (MONTEIRO, 1973 apud BIERAS e SANTOS, 2003). A massa de ar Tropical Continental (quente e seca) ocorre quando o aquecimento da depressão do Chaco é dinamizado pelo avanço da Frente Polar Atlântica. Ela se origina no interior do continente, bloqueando a entrada de frentes frias e nuvens de instabilidades. 
No verão a massa de ar Equatorial Continental (quente e úmida), originada na Amazônia ocidental, é atraída pelos sistemas de baixa pressão da massa tropical continental e da frente polar, atingindo assim o Estado do Paraná. Durante este período do ano os sistemas frontais que se deslocam pela região, estão associados à passagem de sistemas frontais, e também à atuação dos Complexos Convectivos de Mesoescala (CCMs) e os Vórtices Ciclônicos em Altos Níveis (VCAN) (LOURENÇO, 1996), que contribuem para maiores volumes de precipitação, ocasionando chuvas intensas, localizadas e de curta duração.

No outono - inverno, período que se encerra a estação chuvosa, a massa de ar Polar Atlântica (fria e úmida) tem sua maior incidência. Se originando pelo acúmulo de ar polar nas porções do Oceano Atlântico próximo à Patagônia, ela entra no Brasil na retaguarda de frentes frias, que geralmente promovem chuvas e queda na temperatura no ar (SOTÉRIO et al., 2005).

\section{CONCLUSÕES}

O relevo e a dinâmica das massas de ar sobre o continente Sul-Americano têm significativa atuação na distribuição espacial e temporal das chuvas, caracterizando assim as estações chuvosas diferenciadas no Estado do Paraná, de agosto a maio.

A característica da transição climática do Paraná faz com que exista maior diferenciação entre a estação seca e chuvosa no norte e oeste. No sul as chuvas são mais uniformemente distribuídas e se prolongam durante a estação de crescimento das culturas agrícolas.

O número de dias da estação chuvosa variou entre 150 e 210 dias e o volume de precipitação foi de $800 \mathrm{~mm}$ a $1.700 \mathrm{~mm}$.

Conclui-se que o conhecimento do início e fim da estação chuvosa é imprescindível para o planejamento e gerenciamento agrícola, possibilitando a escolha de culturas, estratégias de manejo e épocas de cultivo por região. 


\section{REFERÊNCIAS}

ANDRIOTTI, J. L. S. (2004) Fundamentos de Estatística e Geoestatística. Ed Unisinos. São Leopoldo-RS, 165p.

BARBIERI, P.R.B. Caracterização da estação chuvosa nas regiões sul e sudeste do Brasil associado com a circulação atmosférica. 2005. 118 p. (Mestrado em Meteorologia) Instituto Nacional de Pesquisas Espaciais, São José dos Campos, 2005. Disponível em: http://mtc-m17.sid.inpe.br/col/sid.inpe.br/jeferson/2005/06.01.19.48/doc/publicacao.pdf. acesso em: 22 set. 2007.

BIERAS, R. A.; SANTOS, M. J. Z. dos. Comportamento Climático e incidência do cancro cítrico, na cultura de citros, nos municípios de Limeira e Bebedouro (SP). Revista Estudos Geográficos. Rio Claro, v.1, n.1, jun.2003.

CARAMORI, P.H., GONÇALVES, S.L., WREGE, M.S. et al. Zoneamento de riscos climáticos e definição de datas de semeadura para o feijão no Paraná. Revista Brasileira de Agrometeorologia, Passo Fundo, v.9, n.3, (n ${ }^{\circ}$ Especial: Zoneamento Agrícola), p. 477-485, 2001.

CAVIGLIONE, J.H., KIIHL, L.R.M., CARAMORI, P.H. et al. Cartas climáticas do Paranáedição 2.000, versão 1.0. Londrina: Instituto Agronômico do Paraná, 2000. (VERSÃO EM CD ROM).

LOURENÇO, M. C. M. Vórtices ciclônicos em altos níveis que atuam no sul da América do sul. 1996. 77 p. Dissertação (Mestrado em Meteorologia) - Instituto Nacional de Pesquisas Espaciais, São José dos Campos, 1996.

MAACK, R. Geografia do Estado do Paraná. $3^{\text {a }}$ ed. Curitiba: Imprensa Oficial, 2002.

MACHADO, M.A.M.; SEDIYAMA, G.C.; COSTA, J.M.N.; COSTA, M.H. Duração da estação chuvosa em função das datas de início do período chuvoso para o estado de Minas Gerais. Revista Brasileira de Agrometeorologia, Santa Maria, v. 4, n. 2, p. 73-79, 1996.

MONTEIRO, C.A. F. Clima, in Geografia do Brasil: grande região sul. Rio de Janeiro:IBGE, v.IV, tomo I, 1963.

MONTEIRO, C.A F. Dinâmica climática e as chuvas no Estado de São Paulo.(Estudo geográfico sob a forma de Atlas). São Paulo: Instituto de Geografia, Universidade de São Paulo, 1973.

NERY, J. T.; VARGAS, W.M.; MARTINS, M.L.O. Caracterização da precipitação no estado do Paraná. Revista Brasileira de Agrometeorologia, Santa Maria, v. 4, n. 2, p. 81-89, 1996.

SANSIGOLO, C.A. Análise das precipitações diárias de Piracicaba - SP, visando o planejamento agrícola. In: CONGRESSO BRASILEIRO DE AGROMETEOROLOGIA, VI, 1989, Maceió, AL. Anais..., Maceió. SBA, 1989. p.224-231.

SANSIGOLO, C.A. Variabilidade interanual da estação chuvosa no Estado de São Paulo. Revista Brasileira de Agrometeorologia, Santa Maria, v. 4, n.1, p. 101-105, 1996. 
SANTANA, M.O., SEDIYAMA, G.C., RIBEIRO, A., SILVA, D. D. da. Caracterização da estação chuvosa para o estado de Minas Gerais. Revista Brasileira de Agrometeorologia, v. 15, n.1, p.114-120, 2007.

SILVEIRA, L.M. da. Análise rítmica dos tipos de tempo no Norte do Paraná, aplicada ao clima local de Maringá - Estado do Paraná. 2003. Tese (Doutorado em Geografia Física)Faculdade de Filosofia, Letras e Ciências Humanas, Universidade de São Paulo, São Paulo, 2003.

SOTÉRIO, P. W.; PEDROLLO, M. C.; ANDRIOTTI, J. L. Mapa de isoietas do Rio Grande do Sul. In: SIMPÓSIO BRASILEIRO DE RECURSOS HÍDRICOS, 16. 2005. João Pessoa. Associação Brasileira de Recursos Hídricos, 2005. CD-ROM. Disponível em:

http://www.cprm.gov.br/rehi/simposio/pa/Mapa\%20de\%20Isoietas\%20do\%20Rio\%20Grande \%20do\%20Sul.pdf. Acesso em: 15 jun. 2008.

VERÍSSIMO, M. E. Z.; MENDONÇA, F.A. Algumas considerações sobre o clima urbano de Curitiba e suas repercussões na saúde da população. Associação Nacional de PósGraduação e Pesquisa em Ambiente e Sociedade. Encontro da Associação Nacional de Pós Graduação e Pesquisa em Ambiente e Sociedade. São Paulo, ANPPAS, 2004, p.1-15. Disponível em: http://www.anppas.org.br/encontro_anual/encontro2/GT/GT12/elisa_verissimo.pdf. Acesso em: 15 jun. 2008.

(Recebido em setembro/08. Aceito em dezembro/08) 